\title{
A novel C-terminal mutation resulting in constitutive activation of the Listeria monocytogenes central virulence regulatory factor PrfA
}

\begin{abstract}
Correspondence
Nancy Freitag

nfreitag@uic.edu
\end{abstract}

Received 24 March 2011

Revised 8 July 2011

Accepted 5 August 2011

\author{
Bobbi Xayarath, Jennifer I. Smart, Kimberly J. Mueller \\ and Nancy E. Freitag
}

Department of Microbiology and Immunology, University of Illinois at Chicago, Chicago, IL, USA

\section{INTRODUCTION}

Listeria monocytogenes is a Gram-positive bacterial pathogen that survives in a myriad of diverse environmental conditions that range from the soil and decaying plant matter to the cytosol of mammalian host cells (Czuprynski, 2005; Freitag et al., 2009; Gandhi \& Chikindas, 2007; Gray et al., 2006; Lecuit, 2007; Toledo-Arana et al., 2009). This resilient and highly adaptable bacterium can contaminate food sources and as a result has led to thousands of cases of food-borne illness as well as some of the most expensive food recalls in the USA (Centers for Disease Control and Prevention, 2004; Cossart, 2007; Gandhi \& Chikindas, 2007; Lynch et al., 2006; Mead et al., 2006; Swaminathan et al., 2006; Swaminathan \& Gerner-Smidt, 2007). Once ingested by a susceptible individual, $L$. monocytogenes translocates across the gastrointestinal barrier and disseminates, resulting in severe infections that include meningitis and bacteraemia (Cossart \& Toledo-Arana, 2008; Drevets \& Bronze, 2008; Ramaswamy et al., 2007; Swaminathan \& Gerner-Smidt,

Abbreviations: GUS, $\beta$-glucuronidase; CD, circular dichroism; EMS, ethylene methylsulphonate; EMSA, electrophoretic mobility shift assay; LLO, listeriolysin O; XG, 5-bromo-4-chloro-3-indolyl $\beta$-D-glucuronide.
2007). In pregnant women, L. monocytogenes can cross the fetoplacental barrier and result in abortion, stillbirth or the premature birth of a severely infected infant (Delgado, 2008; Smith et al., 2009; Smith et al., 2008; Swaminathan \& Gerner-Smidt, 2007).

The L. monocytogenes transition from life as a saprophyte to life as an intracellular pathogen requires bacterial recognition of its host environment and an associated increase in the expression of a number of genes whose products are required for cell invasion, phagosomal membrane disruption, cytosolic replication and bacterial spread to neighbouring host cells (Cossart \& Toledo-Arana, 2008; Dussurget, 2008; Freitag et al., 2009; Gray et al., 2006; Kreft et al., 2002; Scortti et al., 2007; Toledo-Arana et al., 2009; VázquezBoland et al., 2001). The majority of L. monocytogenes gene products that are known to be required for host infection are regulated by a central virulence regulatory protein known as PrfA (Freitag, 2006; Scortti et al., 2007). PrfA exists in a lowactivity form in bacteria growing outside of host cells, but becomes highly activated via an unknown mechanism following host cell entry (Freitag et al., 2009; ShetronRama et al., 2002, 2003). Activation of PrfA is required for $L$. monocytogenes pathogenesis, and the transition of PrfA from 
a low-activity to a high-activity form is thought to serve as a critical switch enabling $L$. monocytogenes to exploit its intracellular replication niche.

PrfA is a $27 \mathrm{kDa}$ protein which belongs to the cAMP receptor protein (Crp)-Fnr family of transcriptional regulators (Eiting et al., 2005; Lampidis et al., 1994; Vega et al., 1998). Members of this family appear to require the binding of a small molecule cofactor in order to induce an allosteric change that leads to protein activation (Harman, 2001). While the identity of the putative PrfA cofactor remains unknown, a number of mutations have been identified within PrfA that appear to result in protein activation in the absence of cofactor binding ( $p r f A^{*}$ mutations) (Miner et al., 2008a, b; Ripio et al., 1997; Shetron-Rama et al., 2003; Vega et al., 2004; Wong \& Freitag, 2004). These mutations map to different regions of $\operatorname{prfA}$, but have generally clustered either near the putative PrfA cofactor binding site or near residues spanning amino acids 140-155 in the PrfA coding sequence. The most well characterized $\operatorname{prfA} A^{*}$ mutation, $\operatorname{prfA}$ G145S, induces the repositioning of the PrfA helix-turn-helix DNA-binding domain and results in a substantial increase in PrfA DNAbinding affinity (Eiting et al., 2005; Ripio et al., 1997; Vega et al., 1998). Substitutions at L140 also dramatically increase PrfA DNA binding (Miner et al., 2008b; Wong \& Freitag, 2004); however, the mechanisms leading to PrfA activation for other mutations (Y63C, E77K and G155S) are less clear (Miner et al., 2008b; Mueller \& Freitag, 2005). What has become apparent is that PrfA activation results in a variety of $L$. monocytogenes physiological changes that increase bacterial fitness within an infected host while decreasing fitness in broth culture (Bruno \& Freitag, 2010; Wong \& Freitag, 2004). Strains containing $p r f A^{*}$ mutations are hyperinvasive for tissue culture cells and hypervirulent in murine models of infection (Bruno \& Freitag, 2010; Freitag \& Portnoy, 1994; Mueller \& Freitag, 2005); however, the mutants are defective in flagella-mediated swimming motility and are more susceptible to both acid and salt stress (Bruno \& Freitag, 2010; Port \& Freitag, 2007; Shetron-Rama et al., 2003; Wong \& Freitag, 2004). Environment-responsive regulation of PrfA activation thus appears essential for maximizing L. monocytogenes fitness both inside and outside of host cells.

While PrfA shares extensive structural homology with its well-studied family member Escherichia coli Crp, it differs from Crp in having an extended C-terminal domain consisting of three alpha helices (Eiting et al., 2005; Lampidis et al., 1994). This extended C-terminal domain has been postulated to stabilize PrfA DNA binding, and purified PrfA protein does indeed bind DNA with higher affinity than purified Crp lacking its cAMP cofactor (Eiting et al., 2005; Herler et al., 2001; Lampidis et al., 1994; Scortti et al., 2007; Vega et al., 1998). A mutation within the C terminus of PrfA (K220T) has been reported to inactivate PrfA (Roche et al., 2003; Velge et al., 2007), as have deletions at the $\mathrm{C}$ terminus (Herler et al., 2001). Here we present the characterization of a novel prfA P219S mutation within the extended C-terminal region of PrfA that serves to constitutively activate the protein, thus confirming a role for this region in the regulation of PrfA activity.

\section{METHODS}

Bacterial strains, plasmids and growth conditions. L. monocytogenes and E. coli strains used in this study are listed in Table 1. E. coli XL1-Blue (Agilent Technologies), One Shot TOP10 (Invitrogen), NEB $5 \alpha F^{\prime} I^{\mathrm{q}}$ (New England Biolabs) and SM10 were used as host strains for maintenance and propagation of recombinant plasmids. $L$. monocytogenes and $E$. coli strains were grown at $37{ }^{\circ} \mathrm{C}$ in brain heart infusion (BHI) media (Difco) and Luria broth (LB) (Invitrogen). Bacteria containing the L. monocytogenes integration plasmid pPL2 (Lauer et al., 2002) were maintained on media containing chloramphenicol $(25 \mu \mathrm{g} \mathrm{m})^{-1}$ for $E$. coli and $7.5 \mu \mathrm{g} \mathrm{ml} \mathrm{m}^{-1}$ for $L$. monocytogenes). Bacteria containing the $6 \times$ histidine-tagged vector pQE30 (Qiagen) were maintained in E. coli with $100 \mu \mathrm{g}$ ampicillin $\mathrm{ml}^{-1}$. Streptomycin $\left(200 \mu \mathrm{g} \mathrm{ml}^{-1}\right)$ was used in selection of $L$. monocytogenes following bacterial conjugation and for isolation of bacteria from infected mice.

Ethylene methylsulphonate (EMS) mutagenesis and $\boldsymbol{\beta}$-glucuronidase assays. L. monocytogenes strain NF-L1124 containing an actA-gus-neo reporter fusion was chemically mutagenized using EMS (Sigma-Aldrich) as described previously (Shetron-Rama et al., 2003). Bacteria expressing high levels of actA were selected on indicator plates containing $50 \mu \mathrm{g} 5$-bromo-4-chloro-3-indolyl $\beta$-D-glucuronide (XG) $\mathrm{ml}^{-1}$ and $10 \mu \mathrm{g}$ neomycin $\mathrm{ml}^{-1}$. Mutants that formed blue colonies on the XG indicator plates and were neomycin-resistant (in contrast with the wild-type which formed white colonies and were neomycin-sensitive) were selected for further analysis. Quantitative liquid culture enzymic assays for $\beta$-glucuronidase (GUS) activity were performed to confirm the increase in actA promoter expression levels. For GUS assays, overnight cultures of L. monocytogenes were diluted $1: 50$ in fresh $\mathrm{BHI}$ and grown with shaking at $37^{\circ} \mathrm{C}$. At various time points, the $\mathrm{OD}_{600}$ was determined for each culture and $1 \mathrm{ml}$ of each sample was centrifuged to recover bacteria. Bacterial pellets were resuspended in $1 \mathrm{ml} \mathrm{ABT}$ buffer $[1 \mathrm{M}$ potassium phosphate $(\mathrm{pH} 7.0)$, $0.1 \mathrm{M} \mathrm{NaCl}, 1 \%$ Triton] and GUS activity was measured as described by Youngman (1987) with the substitution of 4-methylumbelliferyl $\beta$ D-glucuronide (Sigma-Aldrich) in place of 4-methylumbelliferyl $\beta$-Dgalactoside. The prfA promoter and coding regions of the strains that showed an increase in actA-gus-neo activity over wild-type levels were amplified by PCR and their DNA sequences were obtained.

Plasmid and bacterial mutant construction. The prfA P219S mutation was introduced into plasmid pNF1019, a pPL2 site-specific phage integration plasmid containing a wild-type copy of prfA with all promoters required for expression (Wong \& Freitag, 2004), using the Quick Change site-directed mutagenesis kit (Stratagene) with primer pairs 5'-CTCAAAAGATATGCCTCTAAATTAGATGAATGGTTTTATTTAGCATGTCC-3' and 5'-GGACATGCTAAATAAAACCATTCATCTAATTTAGAGGCATATCTTTTGAG-3'. Letters in bold type indicate the mutagenesis of proline (CCT) to serine (TCT) on both forward and reverse strands. The resulting plasmid, pNF1163, was conjugated into strain NF-L1003, which contains an in-frame deletion within $\operatorname{prfA}$ as well as the actA-gus reporter gene fusion, resulting in strain NF-L1452. For generation of purified PrfA proteins, the coding sequence of prfA was amplified by PCR from $L$. monocytogenes strains 10403S (wild-type), prfA P219S (NF-L1452) and prfA G145S (NFL1226) using primer pairs 5'-AAAGGTACCAACGCTCAAGCAGAAG-3' and 5'-GGCTGCAGTTTAATTTAATTTTCCCCAAG-3' and cloned into a pQE30 Expression vector (Qiagen), which contains an 
Table 1. Bacterial strains and plasmids used in this study

\begin{tabular}{|lll|}
\hline Strain or plasmid & \multicolumn{1}{c|}{ Description } & Source or reference \\
\hline Strains & & Miner et al. (2008a) \\
NF-L1124 & L. monocytogenes 10403 S actA-gus-neo-plcB & Wong \& Freitag (2004) \\
NF-L1003 & L. monocytogenes $\Delta$ prfA in 10403S actA-gus-plcB & Wong \& Freitag (2004) \\
NF-L1041 & L. monocytogenes NF-L1003 with pPL2-prfA & Port \& Freitag (2007) \\
NF-L1226 & L. monocytogenes NF-L1003 with pPL2-prfA G145S & This work \\
NF-L1452 & L. monocytogenes NF-L1003 with pPL2-prfA P219S & Agilent Technologies \\
XL1-Blue & E. coli cloning strain & New England Biolabs \\
NEB $5 \mathrm{~F}^{\prime} \mathrm{I}^{q}$ & E. coli protein expression strain & \\
Plasmids & & Qiagen \\
pQE30 & N-terminal His-tagged expression vector & Wong \& Freitag (2004) \\
pNF1019 & pPL2 site-specific integration vector with full-length prfA and all promoters & Port \& Freitag (2007) \\
pNF1223 & pNF-1019 prfA G145S & This work \\
pNF1163 & pNF-1019 prfA P219S & This work \\
pNF1797 & pQE30 prfA P219S & This work \\
pNF2076 & pQE30 prfA wild-type & This work \\
pNF3028 & pQE30 prfA G145S & \\
\hline
\end{tabular}

$\mathrm{N}$-terminal $6 \times$ histidine tag and an IPTG-inducible promoter. Letters in bold type indicate the second codon and stop codon of the prfA coding sequence and italicized letters indicate the KpnI and PstI restriction endonuclease sites used for cloning the PCR fragment into pQE30. The resulting construct was initially propagated in E. coli TOP10 cells, isolated and then transformed into NEB $5 \alpha \mathrm{F}^{\prime} I^{\mathrm{q}}$. An overnight culture containing the expression construct was diluted $1: 50$ in fresh LB broth and the culture was incubated at $37{ }^{\circ} \mathrm{C}$ (with shaking) until an $\mathrm{OD}_{600}$ of 0.5 was reached. To induce expression of the PrfA protein, $1 \mathrm{mM}$ IPTG (Inalco) was added to the culture and induction was allowed to proceed for 3-4 h. The bacterial cells were recovered by centrifugation followed by sonication with four repeated $10 \mathrm{~s}$ bursts and $1 \mathrm{~min}$ cooling on ice. The soluble fraction containing the $\mathrm{N}$-HisPrfA protein was collected and purified using the His-Pur Purification kit (Thermo Scientific). Protein concentration was determined using a BCA Protein Assay kit (Thermo Scientific).

Assessment of growth in broth culture. Overnight cultures of strains grown in BHI were resuspended in fresh BHI media at a dilution of $1: 20$ and growth at $37{ }^{\circ} \mathrm{C}$ with shaking was assessed by measuring the $\mathrm{OD}_{600}$ at the indicated time points.

Measurement of haemolytic activity. Stationary-phase bacterial cultures were diluted $1: 10$ into LB medium and grown at $37^{\circ} \mathrm{C}$ for $5 \mathrm{~h}$ with shaking. $\mathrm{OD}_{600}$ was determined, cultures were normalized to $\mathrm{OD}_{600} 0.5$ and $1 \mathrm{ml}$ of each culture was centrifuged at $13000 \mathrm{~g}$ for $5 \mathrm{~min}$. The supernatant was collected and was assayed for haemolytic activity with sheep erythrocytes washed with PBS (Gibco), as described previously (Camilli et al., 1989). Haemolytic activity was determined as the reciprocal of the supernatant dilution at which $50 \%$ lysis of erythrocytes was observed.

Assessment of phospholipase activity. plcB-dependent phospholipase production was assayed on egg yolk agar plates (Alonzo et al., 2009; Mueller \& Freitag, 2005). Antibiotic-free chicken egg yolk was added in a $1: 1(\mathrm{v} / \mathrm{v})$ ratio to PBS and vortexed to form a suspension. A $5 \mathrm{ml}$ aliquot of egg yolk suspension was added to $100 \mathrm{ml}$ molten LB medium plus $0.2 \%$ activated charcoal (Sigma-Aldrich) and $25 \mathrm{mM}$ glucose-6-phosphate (Sigma-Aldrich) (Bitar et al., 2008); $10 \mathrm{ml}$ of this mixture was poured into Petri dishes. Bacterial strains were gently streaked onto the surface of the plate and incubated at $37^{\circ} \mathrm{C}$ for $48 \mathrm{~h}$. Phospholipase activity was visualized as a zone of opacity surrounding bacterial streaks.
Western blot analysis of PrfA protein. PrfA was detected within cytoplasmic fractions isolated from bacterial whole-cell extracts. A $25 \mathrm{ml}$ culture of each L. monocytogenes strain was grown to midexponential phase in $\mathrm{BHI}$ at $37^{\circ} \mathrm{C}$ with shaking. Cells were normalized to $\mathrm{OD}_{600} 0.8$ and centrifuged and the bacterial pellets were resuspended in $1 \mathrm{ml}$ PBS. Mutanolysin (100 U; Sigma-Aldrich) was added and the suspension was incubated at $37{ }^{\circ} \mathrm{C}$ for $2 \mathrm{~h}$. A $10 \mu \mathrm{l}$ volume of $100 \times$ Protease Inhibitor Cocktail (Calbiochem) was added to the mutanolysin-treated cells, followed by sonication with three $40 \mathrm{~s}$ pulses with 2 min cooling on ice in between each pulse. Cellular debris was centrifuged at $24000 \mathrm{~g}$ for $20 \mathrm{~min}$ at $4{ }^{\circ} \mathrm{C}$ and the supernatant containing the cytoplasmic components was collected and stored at $-20{ }^{\circ} \mathrm{C}$ until further use. For detection of PrfA, $10 \mu \mathrm{l}$ of the isolated cytoplasmic fraction was mixed with $10 \mu \mathrm{l} 2 \times$ Laemmli sample buffer (Bio-Rad), boiled for $5 \mathrm{~min}$ then separated by SDSPAGE. Protein samples were transferred onto PVDF membranes. PrfA was detected using a 1:500 dilution of a monoclonal antibody directed against PrfA in $1 \times$ PBST (PBS plus $0.05 \%$ Tween-20) followed by incubation with a $1: 2500$ dilution of a polyclonal goatanti-mouse secondary antibody conjugated to alkaline phosphatase (SouthernBiotech). Bands were visualized colorimetrically with the addition of $10 \mathrm{ml}$ BCIP/NBT Plus solution (SouthernBiotech). Densitometry was determined using ImageJ software (http://rsbweb. nih.gov/ij/download.html).

Limited proteolysis. Limited proteolytic digestion of His-purified proteins with subtilisin (Sigma-Aldrich) was done as previously described by Miner et al. (2008b) with slight modifications. In brief, $2 \mu \mathrm{g}$ purified protein was incubated with $500 \mathrm{ng}$ subtilisin for 10 and $30 \mathrm{~min}$ at room temperature followed by the addition of $1 \mathrm{mM}$ PMSF to terminate the reaction. Samples were boiled for $5 \mathrm{~min}$ in SDSloading buffer and fragments were separated by SDS electrophoresis on a NuPAGE $4-12 \%$ Bistris gel (Invitrogen). Bands were visualized by staining with Bio-Safe Coomassie G-250 (Bio-Rad).

Circular dichroism (CD). His-purified protein was purified and isolated as described above (Plasmid and bacterial mutant construction). Following purification, eluted protein samples were dialysed in $10 \mathrm{mM} \mathrm{NaH}_{2} \mathrm{PO}_{4}(\mathrm{pH} 8)$ overnight at $4{ }^{\circ} \mathrm{C}$ and the concentration of the dialysed protein that remained in solution was determined using a BCA protein assay kit (Thermo Scientific). Samples $(400 \mu \mathrm{l})$ containing $250 \mu \mathrm{g}$ purified protein $\mathrm{ml}^{-1}$ were then analysed at room temperature on a Jasco J-710 CD spectrometer (UIC Center for 
Structural Biology, Chicago, Illinois) in a $2 \mathrm{~mm}$ rectangular quartz cuvette. CD spectra parameters were set to read at wavelengths between 180 and $310 \mathrm{~nm}$, continuous scanning mode, $2 \mathrm{~nm}$ data pitch, a scanning speed of $100 \mathrm{~nm} \mathrm{~s}^{-1}$, response of $1 \mathrm{~s}$, band width of $1.0 \mathrm{~nm}$ and an accumulation of 3. Data analysis was done using the SpectraManager software program.

Protein chemical cross-linking. Chemical cross-linking was done as previously described by Miner et al. (2008b) with minor modifications. In brief, after separation of samples by SDS-PAGE, proteins were transferred to PVDF membranes. Proteins were detected using a 1:500 dilution of a monoclonal antibody directed against PrfA in $1 \times$ PBST followed by incubation with a $1: 2500$ dilution of a polyclonal goat-anti-mouse secondary antibody conjugated to alkaline phosphatase (SouthernBiotech). Bands were visualized colorimetrically with the addition of a BCIP/NBT Plus solution (Southern Biotech).

Electrophorectic mobility shift assays (EMSAs). Primer pairs used to amplify the $h l y$ promoter DNA fragment $(\sim 100 \mathrm{bp})$ were $5^{\prime}$ TCCTATCTTAAAGTGACTTTATGTT- $3^{\prime}$ and $5^{\prime}$-GCTTCTAAAGATGAAACGCAATATTA-3'. The $3^{\prime}$ end primer was purchased with a biotin label (Sigma-Aldrich). EMSAs were done as described previously (Miner et al., 2008b) with slight modifications. In brief, after DNA-binding reactions and electrophoresis, protein/DNA samples were transferred onto nylon membranes followed by detection using the Pierce chemiluminescent nucleic acid detection module (Thermo Scientific).

Intracellular growth. Bacterial intracellular growth assays in Potorous tridactylis kidney epithelial cells (PtK2) were performed as described previously (Marquis et al., 1995; Mueller \& Freitag, 2005; Wong \& Freitag, 2004; Xayarath et al., 2009). In brief, monolayers of cells were grown on glass coverslips to confluence and infected with bacterial strains with an m.o.i. of $100: 1$. One hour after infection of PtK2 cells, monolayers were washed three times in PBS and $5 \mu \mathrm{g}$ gentamicin $\mathrm{ml}^{-1}$ was added to kill extracellular bacteria. At the indicated time points, coverslips were removed and tissue culture cells were lysed in $5 \mathrm{ml}$ sterile $\mathrm{H}_{2} \mathrm{O}$ to release intracellular bacteria for enumeration of intracellular growth, or the coverslips were processed for microscopy.

Plaque assays. Plaque assays were conducted as described previously (Sun et al., 1990). Briefly, murine L2 fibroblasts were grown to confluence in six-well microtitre plates and infected with $20 \mu \mathrm{l}$ of a normalized 1:20 dilution of overnight culture grown at $37^{\circ} \mathrm{C}$ in BHI with shaking (m.o.i. 10:1). One hour post-infection, L2-infected monolayers were washed and $5 \mu \mathrm{g}$ gentamicin $\mathrm{ml}^{-1}$ was added to kill extracellular bacteria. Three days post-infection, Neutral Red (Sigma-Aldrich) was added and plaques were visualized and measured using a micrometer (Finescale).

Mouse infections. All animal procedures were approved by the Institutional Animal Care and Use Committees (IACUC) and performed in the Biological Resources Laboratory at the University of Illinois at Chicago. Overnight bacterial cultures were diluted $1: 20$ into fresh media and grown to $\mathrm{OD}_{600} \sim 0.6$. A $1 \mathrm{ml}$ volume of culture (corresponding to $6 \times 10^{8}$ c.f.u. $\mathrm{ml}^{-1}$ ) was washed, diluted and resuspended in PBS to a final concentration of $1 \times 10^{5}$ c.f.u. $\mathrm{ml}^{-1}$. Female 8-10-week-old ND4 Swiss Webster mice (Harlan Laboratories) received injections of $200 \mu \mathrm{l}$ PBS containing $2 \times 10^{4}$ c.f.u. $L$. monocytogenes via the tail vein. Mice were killed and livers and spleens were harvested $72 \mathrm{~h}$ post-infection. Organs were homogenized with a Tissue Master 125 homogenizer (Omni International) and dilutions were plated onto BHI streptomycin $\left(200 \mu \mathrm{g} \mathrm{ml}^{-1}\right)$ plates.

Swimming motility assays. Swimming motility was evaluated on semisolid $[0.3 \%(\mathrm{w} / \mathrm{v})$ agar] BHI medium. The plates were inoculated with $5 \mu$ mid-exponential phase $\left(\mathrm{OD}_{600} \sim 0.6\right)$ bacterial cultures grown in BHI at $37^{\circ} \mathrm{C}$. Inoculated plates were then incubated at $37{ }^{\circ} \mathrm{C}$ for $48 \mathrm{~h}$. The diameter of the swimming colony in millimetres was measured at various time points, and swimming motility was expressed in millimetres travelled from the edge of the original drop diameter of inoculation. Each strain was assayed in triplicate.

\section{RESULTS}

\section{Identification of a novel prfA* mutation within the extended C-terminal region of PrfA}

To identify unique and previously uncharacterized mutations resulting in the constitutive activation of PrfA, a $L$. monocytogenes strain containing an actA-gus-neo-plcB transcriptional reporter gene fusion was mutagenized with EMS, a chemical mutagen that most commonly induces G/ $\mathrm{C}$ to $\mathrm{A} / \mathrm{T}$ transitions. L. monocytogenes mutants exhibiting activation of PrfA activity were selected based on high-level actA promoter expression as indicated by increased levels of neomycin resistance and by enhanced blue colony colour on indicator plates containing the GUS substrate XG. Out of approximately $1 \times 10^{10}$ total bacteria present in six independently EMS-treated pools, 282 mutants were isolated as dark blue neomycin-resistant colonies. The prfA promoter and coding regions of 60 of these isolates were sequenced. A total of 42 mutants contained mutations within $\operatorname{prf} A$, with the largest group (46\%) containing the previously described $\operatorname{prfA}^{*}$ G145S mutation. Other previously described $\operatorname{prfA} A^{*}$ mutations were also identified (prfA L140F, G155S and E77K). Only one of the 42 sequenced mutants possessed a novel $\operatorname{prfA}$ mutation not previously associated with PrfA* activity; this mutant contained a $\mathrm{C}$ to $\mathrm{T}$ transition resulting in a serine substitution for a proline at position 219 (P219S). This mutant was selected for further analysis.

Based on the PrfA crystal structure (Eiting et al., 2005), the prfA P219S mutation is located in $\alpha \mathrm{H}$, one of the three Cterminal alpha helices present in PrfA but absent from Crp (Fig. 1a). These three alpha helices have been proposed to stabilize the C-terminal PrfA DNA-binding domain and to participate in homodimer interactions, such that residues within the three helices of one monomer form hydrogen bonds to $\beta$ loops of the second monomer (Eiting et al., 2005; Herler et al., 2001). The proline residue at position 219 is the first amino acid of the $\alpha \mathrm{H}$ helix, contributing to the transition from $\alpha \mathrm{G}$ to $\alpha \mathrm{H}$ (Fig. 1a).

\section{The prfA P219S mutation results in constitutive activation of PrfA}

The prfA P219S mutation was introduced into a $L$. monocytogenes $\triangle p r f A$ actA-gus-plcB strain as a single copy on plasmid pPL2 to confirm that the mutation was sufficient to confer PrfA activation. In addition to prfA P219S, wild-type prfA and prfA G145S were also introduced into $\triangle p r f A$ actA-gus-plcB strains as single copies using the plasmid integration vector pPL2 which contains all three promoters required for full prfA expression and 

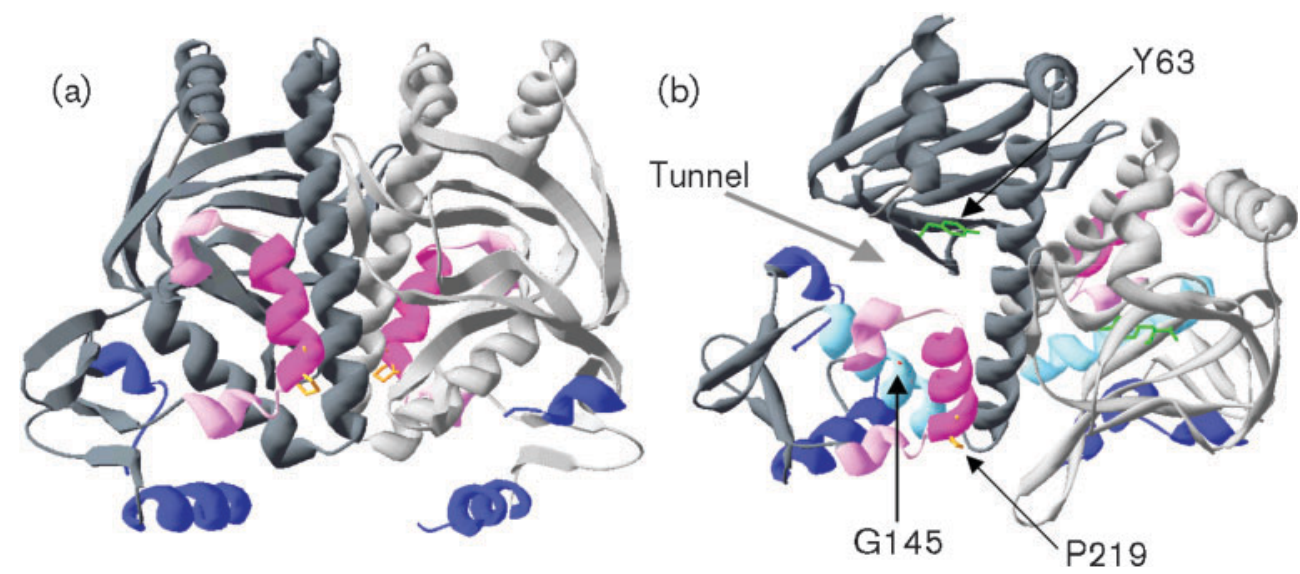

Fig. 1. Location of the PrfA P219S mutation. (a) Ribbon modelling of the PrfA dimer using DeepView-Swiss Pdb viewer v4.0 (http://spdbv.vital-it.ch/). The monomers that make up the dimer are coloured either light or dark grey. The DNA-binding helixturn-helix helices are shown in blue and the three helices unique to PrfA that are located at the distal end of the $\mathrm{C}$ terminus are coloured pink ( $\alpha \mathrm{G}$ and $\alpha \mathrm{l})$ and magenta $(\alpha \mathrm{H})$. The prfA P219S mutation is located in $\alpha \mathrm{H}$ and the proline residue at this specific location is shown in orange. (b) Ribbon modelling as done in (a) highlighting the tunnel suggested by Eiting et al. (2005) to be the putative ligand-binding pocket as indicated by the grey arrow. Colours for domains and secondary structures are the same as in (a), with the addition of $\alpha \mathrm{D}$ shown in light blue. The specific residue $\mathrm{Y} 63$ (in $\beta 5$ ) is shown in green and $\mathrm{G} 145$ (in $\alpha \mathrm{D}$ ) is in red. The G145 side chain is buried within helix D and is difficult to visualize but has been further highlighted by the black arrow pointing to its location.

complementation (Wong \& Freitag, 2004). All comparisons of PrfA activity were thus carried out in isogenic $\triangle p r f A$ act $A-g u s-p l c B$ strains containing either wild-type or mutant alleles of prfA. The introduction of pPL2-prfA P219S resulted in a blue colony colour on plates containing the XG indicator for GUS activity, similar to that observed for strains containing pPL2-prfA G145S (data not shown). Strains containing the prfA P219S allele exhibited no obvious growth defect when grown in broth culture (Fig. 2a), but did display high levels of GUS activity in broth culture, similar to the levels observed for the highly activated prfA* G145S mutant (Fig. 2b). In addition, overnight cultures of the prfA $\mathrm{P} 219 \mathrm{~S}$ strain grown in $\mathrm{BHI}$ at $37^{\circ} \mathrm{C}$ without shaking settled to the bottom of culture tubes, exhibiting a phenotype similar to that reported for other high-activity prfA $A^{\star}$ mutant cultures (Wong \& Freitag, 2004) (data not shown).

The expression of listeriolysin $\mathrm{O}$ (LLO) and the broadrange phospholipase PC-PLC is increased following PrfA activation (Alonzo et al., 2009; Portnoy et al., 1988; Shetron-Rama et al., 2003; Wong \& Freitag, 2004). Consistent with the increase observed for actA promoter activity, the prfA P219S mutant exhibited increased LLO and PC-PLC activity with levels that were similar to those observed for the prfA* G145S mutant (Fig. 2c, d). In addition, Western blot analysis using antibody directed against PrfA indicated that PrfA protein levels were approximately twofold higher in strains containing the prfA P219S and prfA* G145S mutations in comparison with strains containing wild-type prfA (Fig. 3a), a result consistent with increased prfA expression resulting from
PrfA-dependent activation of the upstream plcA-prfA promoter (Camilli et al., 1993; Freitag \& Portnoy, 1994). These data indicate that the prfA P219S mutation results in the constitutive activation of PrfA to a level that resembles that of the highly activated $\operatorname{prfA} A^{*}$ G145S mutant strains.

\section{The prfA P219S mutation alters PrfA conformation}

Previously described $\operatorname{prf} A^{*}$ mutations have been reported to alter PrfA conformation in ways that can be detected by limited proteolytic digestion (Miner et al., 2008b). Limited proteolysis enables a rapid assessment of protein conformational changes that can distinguish between active and inactive forms of $\mathrm{Crp}\left(\mathrm{Crp}^{\star}\right.$ mutants or Crp with or without cAMP) as well as PrfA and PrfA* mutants (Harman et al., 1986; Miner et al., 2008b; Tan et al., 1991). Polypeptide fragments resulting from limited protease digestion were separated by SDS-PAGE and visualized by Coomassie staining (Fig. 3b). Heat-denatured PrfA samples were also subjected to subtilisin digestion to confirm that all protein samples were equally susceptible to proteolytic cleavage when denatured (Fig. 3b, position of subtilisin indicated by arrow). Limited proteolytic digestion of wild-type PrfA, PrfA P219S and PrfA* G145S proteins indicated that both PrfA G145S and PrfA P219S were more susceptible to proteolytic digestion in comparison to the wild-type protein (Fig. 3b). The PrfA P219S protein was also distinguishable from PrfA G145S, indicating that the P219S mutation resulted in PrfA conformational changes that are distinct from those imposed by G145S. 
(a)

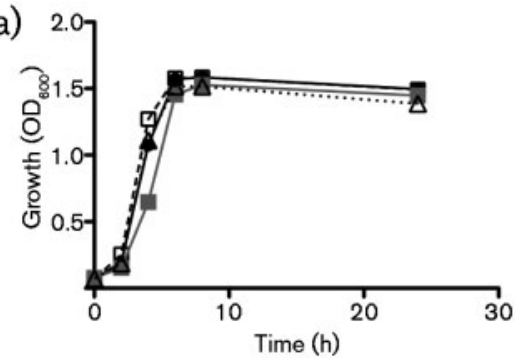

(c) $\frac{\infty}{5}$

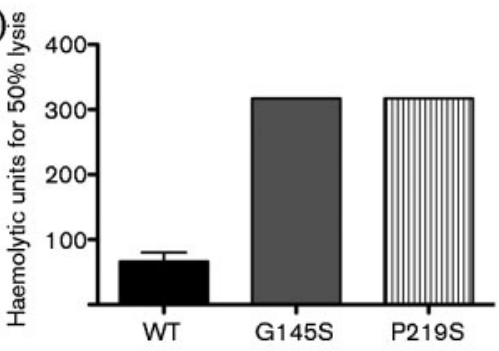

(b)

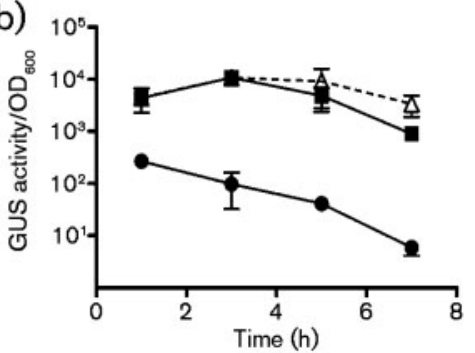

(d)

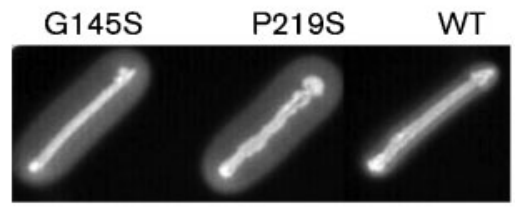

Fig. 2. The prfA P219S mutation dramatically increases PrfA-dependent virulence gene expression in broth culture. (a) Growth curve of the prfA P219S mutant $(\triangle)$ compared with wild-type $(\bullet)$, prfA G145S ( $\square$ ) and a $\triangle$ prfA strain ( $\square$ ). Overnight cultures of strains grown in $\mathrm{BHI}$ were diluted $1: 20$ in fresh $\mathrm{BHI}$ and grown at $37{ }^{\circ} \mathrm{C}$ with shaking and the $\mathrm{OD}_{600}$ was measured at the indicated time points. The prfA P219S mutant grew similarly to all strains grown in rich media. (b) PrfA-dependent activation of act $A$ expression as indicated by GUS activity. L. monocytogenes strains containing act $A$-gus transcriptional reporter fusions in the presence of prfA G145S ( $\boldsymbol{\square})$, prfA P219S $(\triangle)$ or wild-type prfA $(\bullet)$ were grown in $\mathrm{BHI}$ at $37{ }^{\circ} \mathrm{C}$ with shaking. GUS activity indicative of act $A$ expression was assessed at the indicated time points. Each data point is the mean $\pm 95 \%$ confidence interval GUS activity measured in duplicate and the data shown are representative of at least two independent experiments. (c) Detection of PrfA-dependent LLO-associated haemolytic activity. Secreted LLO activity was assessed by measuring lysis of sheep erythrocytes from serial dilutions of bacterial culture supernatants. Haemolytic activity is represented as the reciprocal of the supernatant dilution at which $50 \%$ lysis of erythrocytes was observed. Data shown represent the mean \pm SEM activity measured in triplicate for two independent experiments. (d) Detection of PrfA-dependent PC-PLC activity. PC-PLC-associated phospholipase activity was assessed on egg yolk agar plates containing $0.2 \%$ activated charcoal and $25 \mathrm{mM}$ glucose $6-$ phosphate following incubation at $37{ }^{\circ} \mathrm{C}$ for $24 \mathrm{~h}$. The white precipitate surrounding the bacterial streak is indicative of PC-PLC activity. Data are representative of at least three independent experiments.

To further assess conformational changes conferred by the P219S mutation, CD was used to compare protein secondary structure. Interestingly, both the PrfA P219S and PrfA G145S proteins exhibited similar CD profiles that were distinct from the spectrum observed for wild-type PrfA (Fig. 3c). PrfA P219S and PrfA G145S exhibited a more negative signal in the $208-222 \mathrm{~nm}$ range when compared with wild-type PrfA, suggestive of a higher alpha helical content. Thus, while PrfA P219S can be structurally distinguished from both wild-type PrfA and PrfA G145S via limited protease digestion, $\mathrm{CD}$ analysis suggests that overall PrfA P219S may adopt a confirmation more closely related to that of the constitutively activated PrfA G145S mutant than that of wild-type PrfA.

\section{The prfA P219S mutation modestly reduces PrfA dimer formation}

PrfA crystal structure analysis indicates that PrfA forms homodimers, and homodimers have also been observed via chemical cross-linking (Eiting et al., 2005; Velge et al., 2007). Mutationally activated forms of PrfA form homodimers; however, this homodimer formation is reduced in comparison with the wild-type protein (Miner et al., 2008b). To assess the ability of purified PrfA P219S to form homodimers in vitro, purified protein was incubated with two distinct chemical cross-linking agents [sulpho-ethylene glycol bis[succinimidylsuccinate] and Bis suberate $\left(\mathrm{BS}^{3}\right)$ ] and analysed by SDS-PAGE gel electrophoresis. Wild-type PrfA protein was observed to readily form dimers under these conditions, whereas the PrfA $^{*}$ G145S mutant exhibited reduced dimer formation as expected (Fig. 3d, the similar BS $^{3}$ data are not shown). Interestingly, despite its resemblance thus far in other assays to highly activated forms of PrfA, the PrfA P219S mutant formed dimers with an efficiency that was somewhat less than that of wild-type PrfA but greater than that of PrfA G145S.

\section{PrfA P219S modestly enhances PrfA DNA-binding affinity}

Highly activated PrfA G145S and PrfA L140F mutant proteins bind target DNA with an affinity that is 
(a)

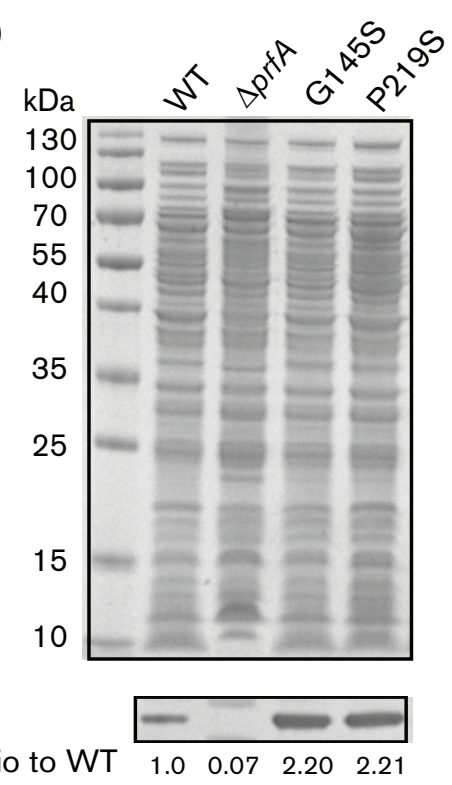

(c)

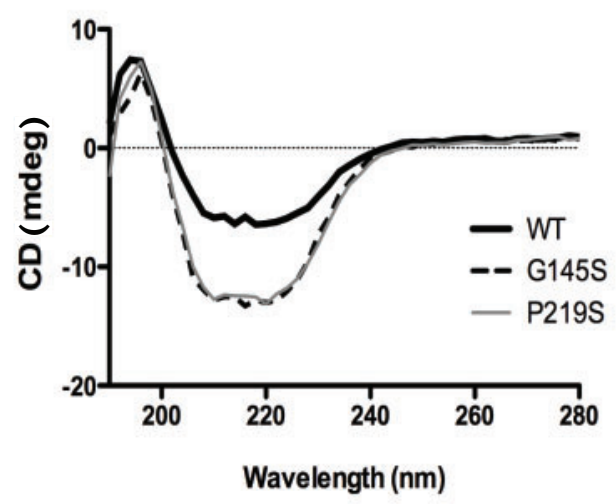

(b)
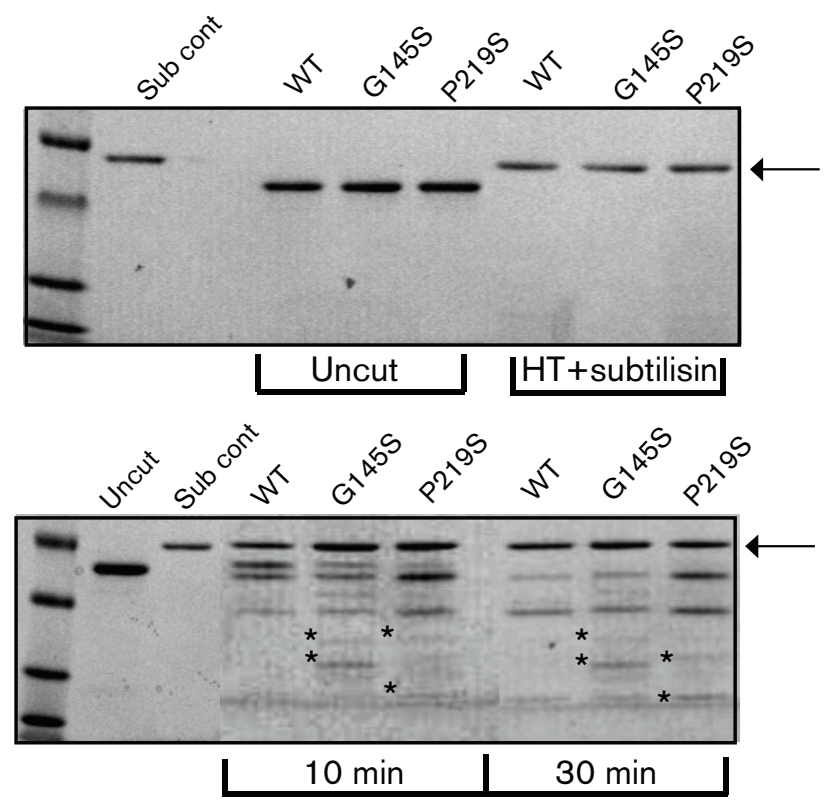

(d)

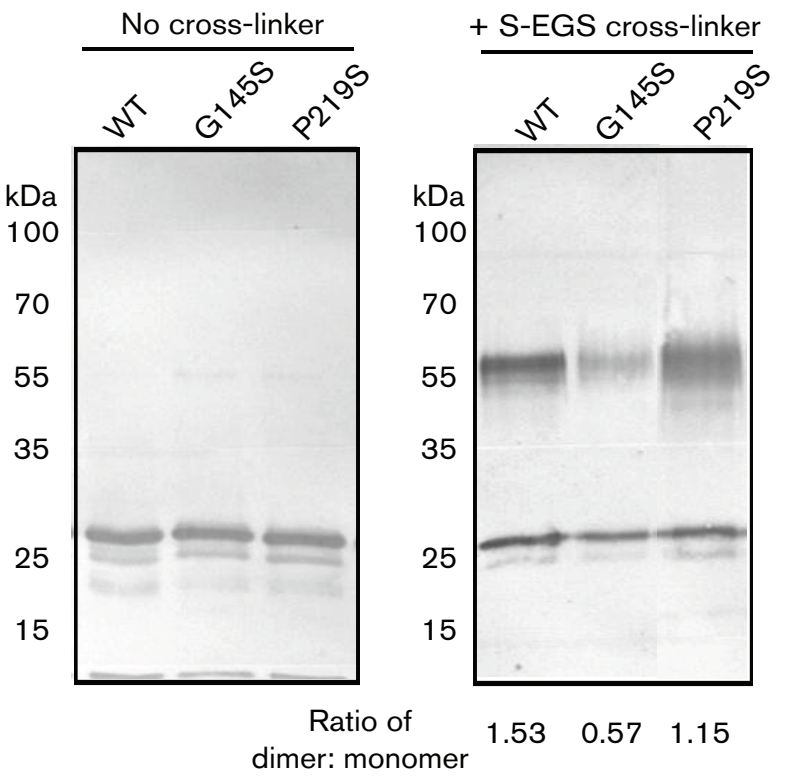

Fig. 3. The prfA P219S mutation influences PrfA protein conformation and dimer formation. (a) Western blot analysis of PrfA protein. Top panel: $20 \mu \mathrm{l}$ isolated bacterial cytoplasmic fractions, normalized based on cell density, were loaded onto a $12 \%$ BisTris polyacrylamide gel and proteins were separated by gel electrophoresis. Polypeptides were visualized by staining with Coomassie blue. Bottom panel: PrfA protein was detected in the cytoplasmic fractions of the various $L$. monocytogenes strains using a monoclonal antibody directed against PrfA. Approximately twofold more PrfA protein was detected in both the prfA P219S and G145S mutant strains compared with the wild-type strain. Numbers below the Western panel indicate relative amounts of protein as determined by densitometry using ImageJ software (http://rsbweb.nih.gov/ij/download.html) in comparison to the levels of wild-type PrfA detected. (b) Comparison of PrfA protein conformation by limited proteolytic digestion. Samples (2 $\mu \mathrm{g}$ ) of purified PrfA G145S, PrfA P219S or of the wild-type protein were digested with $500 \mathrm{ng}$ subtilisin for 10 and 30 min at room temperature. Protein fragments were separated by SDS-PAGE and visualized by Coomassie staining. Untreated protein samples (uncut) and heat-denatured samples treated with subtilisin (Sub cont) were included as controls to demonstrate that denatured samples were equally susceptible to enzymic digestion. Arrows indicate the position of subtilisin and asterisks denote fragments that were not observed for the wild-type protein. PrfA P219S was more susceptible to proteolytic digestion than the wild-type protein but was also distinguishable from PrfA G145S. Gels are representative of three independent experiments. (c) CD analysis of the purified PrfA proteins. CD far-UV absorption signals between wavelengths of 180 and $310 \mathrm{~nm}$ were measured for $250 \mu \mathrm{g}$ purified protein $\mathrm{ml}^{-1}$ in $400 \mu \mathrm{l} 10 \mathrm{mM} \mathrm{NaH} \mathrm{PO}_{4}$ at room temperature. The graph is representative of two independent experiments run in triplicate. (d) PrfA homodimer formation as assessed by chemical cross-linking of purified PrfA. Samples (500 ng) of purified PrfA proteins were chemically cross-linked with $10 \mu \mathrm{M}$ sulpho-ethylene glycol bis[succinimidylsuccinate] 
(S-EGS) for $1 \mathrm{~h}$ at room temperature followed by SDS-PAGE and Western blotting for detection of PrfA dimers. The PrfA P219S mutant formed homodimers with an efficiency that was less than that observed for wild-type PrfA but greater than that observed for the PrfA* G145S mutant. The ratio of PrfA dimer to monomer formation was assessed by densitometry using ImageJ software (http://rsb.info.nih.gov/ij/download). Data are representative of at least three independent experiments.

significantly greater than that exhibited by the wild-type protein (Eiting et al., 2005; Miner et al., 2008b; Vega et al., 1998). Given that the extended C-terminal region of PrfA has been proposed to enhance the DNA-binding stability of PrfA, we sought to compare DNA binding between the PrfA P219S mutant with wild-type and highly activated PrfA G145S. EMSAs confirmed that purified PrfA G145S bound a DNA fragment containing the hly promoter with significantly higher affinity than wild-type protein (Fig. 4). Unexpectedly, although the PrfA P219S mutant stimulated high levels of PrfA-dependent hly-encoded LLO activity, the mutant protein displayed only a modest enhancement in DNA-binding activity in comparison with wild-type PrfA (Fig. 4). The PrfA P219S mutation therefore affects PrfA function in a way that is distinct from that of the PrfA G145S mutation.

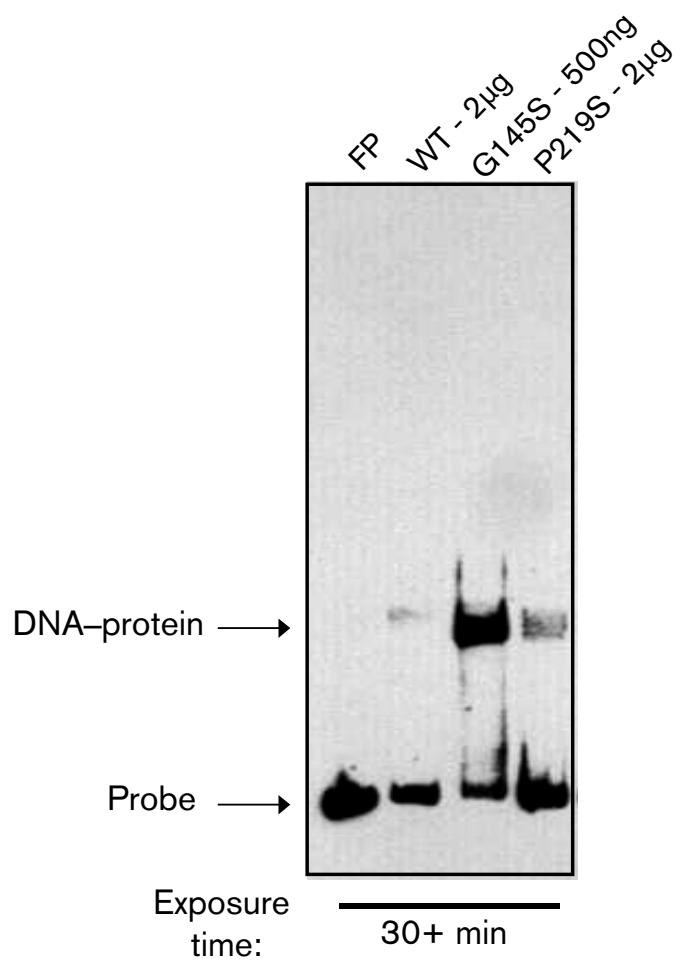

Fig. 4. PrfA P219S does not exhibit high-affinity in vitro DNA binding. The binding of purified PrfA wild-type and mutant protein to a biotin-labelled hly promoter DNA fragment was assessed by EMSA. FP, Free probe, no protein added. Data are representative of at least three independent experiments.

\section{L. monocytogenes prfA P219S strains are hyperinvasive for tissue culture cells}

PrfA activation leads to the increased expression of a number of gene products that contribute to bacterial invasion, including InlA, InlB, ActA and LLO (Freitag et al., 2009; Ireton \& Cossart, 1997; Ramaswamy et al., 2007; Scortti et al., 2007; Vázquez-Boland et al., 2001). Consistent with the ability of the prfA P219S mutation to induce PrfA activation, L. monocytogenes prfA P219S mutants were hyperinvasive for both epithelial and fibroblast cell lines (Fig. 5). Cells infected with the prfA P219S mutants had significantly increased numbers of intracellular bacteria (up to 13-fold higher) at multiple time points post-infection of PtK2 epithelial cells, while the rate of intracellular bacterial replication was similar to that observed for wild-type bacteria (approximately $57 \mathrm{~min}$ doubling time for prfA P219S versus 61 min doubling time for wild-type) (Fig. 5a). Given the similar rate of intracellular bacterial replication, the increased numbers of prfA P219S bacteria at $3 \mathrm{~h}$ after infection ( $2 \mathrm{~h}$ after gentamicin treatment) are consistent with enhanced bacterial invasion of PtK2 epithelial cells. The prfA P219S mutant also appeared hyperinvasive for L2 fibroblast cells as indicated by the increased number of plaques formed by the mutant following the infection of monolayers in comparison with those infected with wildtype L. monocytogenes (Fig. 5b). Approximately 10-fold greater numbers of plaques were formed by the prfA P219S strain versus wild-type bacteria at a similar m.o.i. (Fig. 5b). The prfA P219S mutation therefore serves to enhance bacterial invasion of host cells in tissue culture.

\section{The prfA P219S mutant strain is hypervirulent in mice}

Highly activated $\operatorname{prfA} A^{*}$ mutants have been shown to be hypervirulent in murine models of infection (Bruno \& Freitag, 2010; Wong et al., 2004). When mice were infected with $1 \times 10^{4}$ c.f.u. of either wild-type or the prfA P219S mutant via tail vein injection, approximately 5 - and 10 -fold more bacteria were recovered from the livers and spleens, respectively, of mice infected with the mutant strain (Fig. 6). Taken together, these results clearly indicate that the prfA P219S mutation results in high-level activation of PrfA as well as increased bacterial virulence.

\section{Unlike L. monocytogenes prfA G145S mutants, prfA P219S mutants are not defective for swimming motility}

Outside of host cells, it has been previously demonstrated that $\operatorname{prfA} A^{\star}$ mutants exhibit defects in swimming 
(a)

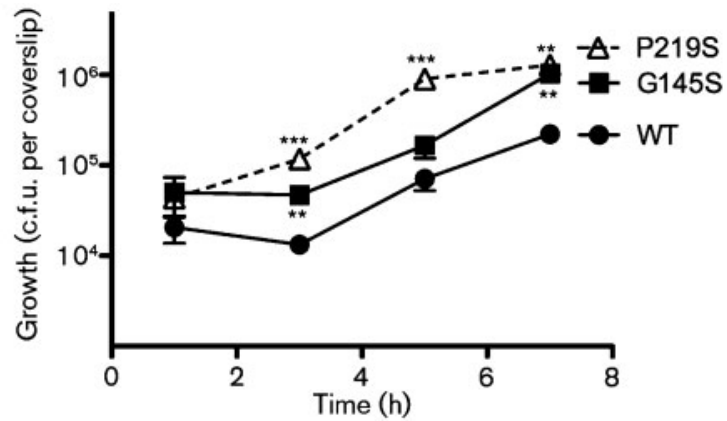

(b)

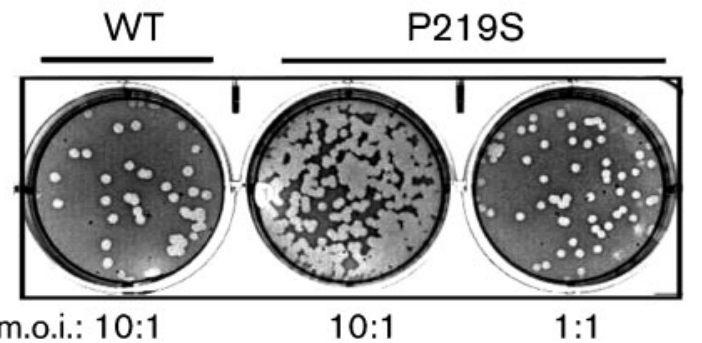

Fig. 5. Strains containing prfA P219S are hyperinvasive for tissue culture cells. (a) Bacterial invasion and intracellular growth in monolayers of PtK2 epithelial cells. PtK2 epithelial cells grown on glass coverslips were infected with the indicated strains at an m.o.i. of $100: 1$. Monolayers were washed and gentamicin was added $1 \mathrm{~h}$ post-infection (p.i.); coverslips were removed at the indicated time points for lysis of host cells and enumeration of intracellular bacteria. The number of bacteria recovered from the prfA P219S mutant was significantly different from the number recovered from the wild-type strain at 3,5 and $7 \mathrm{~h}$ p.i., while the differences between the prfA G145S mutant and wild-type were significant at 3 and $7 \mathrm{~h}$ p.i. ${ }^{\star \star} P \leqslant 0.005,{ }^{\star \star \star} P \leqslant 0.0005$ using an unpaired two-tailed Student's $t$-test (GraphPad Prism v.5.0A). In addition, the P219S mutant was significantly different from the G145S mutant at 3 and $5 \mathrm{~h}$ p.i. $\left({ }^{\star \star} P \leqslant 0.005\right)$. Data shown represent the mean \pm SEM of three independent experiments done in triplicate. (b) Bacterial infection of $\mathrm{L} 2$ fibroblast cells. The ability of the prfA P219S mutant and wild-type L. monocytogenes to invade, multiply and spread cell-to-cell within fibroblast tissue culture cell monolayers was determined by assessing plaque formation following infection with an m.o.i. of $10: 1$ or $1: 1$. At $1 \mathrm{~h}$ p.i. the cells were washed and gentamicin was added. Plaques were visualized 3 days p.i. Data shown are representative of three independent experiments done in duplicate.

motility that can be readily detected in soft agar media (Shetron-Rama et al., 2003; Wong \& Freitag, 2004). Swimming motility defects would be anticipated to compromise bacterial fitness in environments outside of host cells, as well as potentially reducing bacterial invasion of the intestinal epithelium (O’Neil \& Marquis, 2006). It has been reported that gene products that contribute to flagella biosynthesis and chemotaxis, such as FlaA and MotA, are downregulated following PrfA activation, suggesting an inverse relationship between motility and $\operatorname{prfA}$ activity (Port \& Freitag, 2007; Toledo-Arana et al., 2009). To examine the motility of $\operatorname{prfA} \mathrm{P} 219 \mathrm{~S}$ strains, L. monocytogenes

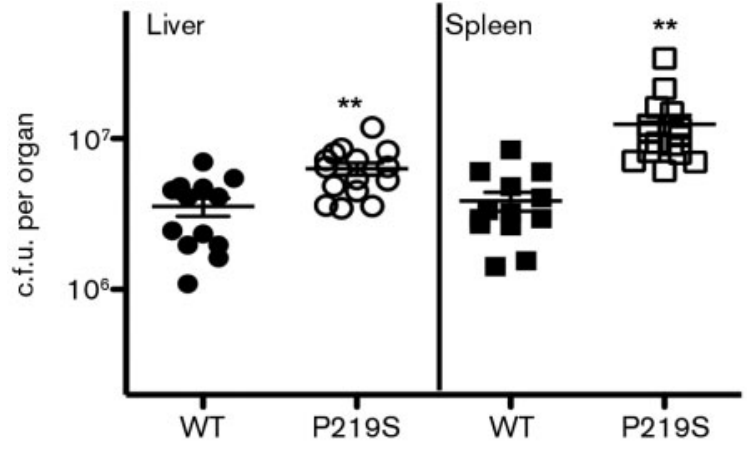

Fig. 6. The L. monocytogenes prfA P219S mutant is hypervirulent in vivo. Swiss Webster mice were intravenously infected with $2 \times 10^{4}$ c.f.u. through the tail vein. The livers and spleens were harvested $48 \mathrm{~h}$ post-infection, homogenized and enumerated for bacterial burdens. Each data point represents one mouse and the solid lines denote the median for each data group. Data were obtained from two independent experiments. Asterisks indicate statistical significance; ${ }^{\star \star} P \leqslant 0.005$ using an unpaired two-tailed Student's $t$-test (GraphPad Prism v.5.0A).

swimming motility was assessed on semisolid BHI media at $37{ }^{\circ} \mathrm{C}$ over the course of 2 days. Defects in the initiation of bacterial swimming motility were readily detectable for $p r f A$ G145S but not for prfA P219S or wild-type strains during the first $24 \mathrm{~h}$ of growth (Fig. 7a). After approximately $24 \mathrm{~h}, \operatorname{prfA}$ G145S strains exhibited rates of swimming motility that were similar to those observed for prfA P219S, wild-type and $\triangle p r f A$ strains (Fig. 7b). These results indicate that PrfA activation does not prohibit the assembly of a functional flagellum nor interfere with bacterial chemotaxis. Interestingly, for strains containing some $p r f A^{\star}$ mutations (such as G145S), PrfA activation delays the initiation of swimming motility, whereas other $p r f A^{*}$ strains (P219S) show no indication of motility defects.

\section{DISCUSSION}

PrfA activation appears to represent a critical switch that enables L. monocytogenes to transition from an environmental bacterium to a pathogen that can access and exploit the mammalian cytosol as a bacterial replication niche (Freitag et al., 2009; Toledo-Arana et al., 2009). While the signal that triggers PrfA activation remains unknown, the isolation of $p r f A^{*}$ mutant strains has provided insight into the effects of PrfA activation on bacterial fitness and physiology (Bruno \& Freitag, 2010; Mueller \& Freitag, 2005; Shetron-Rama et al., 2003; Wong \& Freitag, 2004). Phenotypic characterization of $p r f A^{*}$ mutants has established the critical importance of environmental regulation of PrfA to optimize bacterial survival in distinct habitats both outside and inside mammalian cells. Here we describe the isolation of a novel $p r f A^{*}$ mutation located within the distal Cterminal region of PrfA. This region has not been previously associated with PrfA activation and it is absent from the 

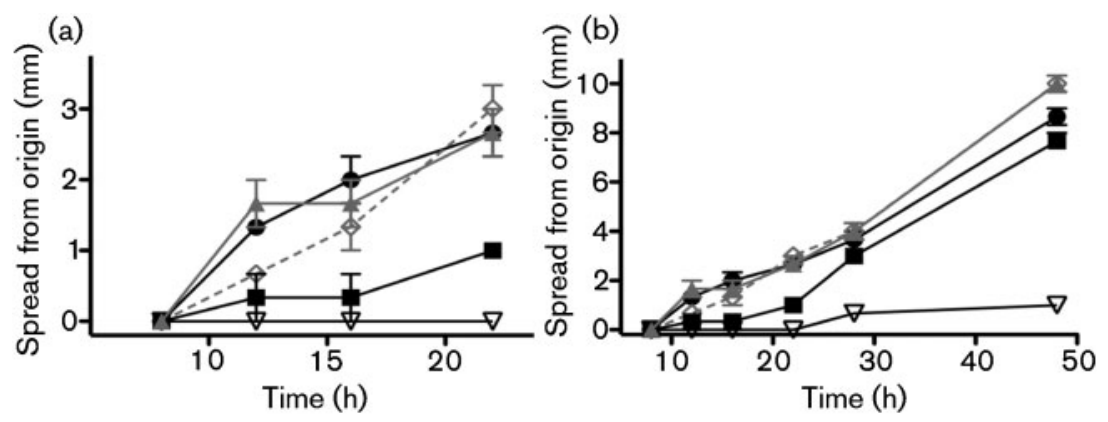

Fig. 7. prfA G145S but not $\mathrm{P} 219 \mathrm{~S}$ strains are delayed for initiation of swimming motility. Measurement of bacterial spread in soft agar. The diameter of bacterial spread (in $\mathrm{mm}$ ) from the original inoculation site was measured at various time points up to $48 \mathrm{~h}$ for plates incubated at $37^{\circ} \mathrm{C}$. A $\triangle$ flaA mutant, which is defective for motility, was used as a negative control. The prfA G145S mutant strain is slow to initiate swimming motility, but then moves at a rate that is similar to that of wild-type, $\operatorname{prf} A$ $\mathrm{P} 219 \mathrm{~S}$ and $p r f A$ deletion strains. - wild-type; $\Delta, \mathrm{P} 219 \mathrm{~S} ; \diamond, \Delta p r f$;, $\mathrm{G} 145 \mathrm{~S} ; \nabla, \Delta f \mathrm{la} A$. structurally related family member Crp (Eiting et al., 2005; Lampidis et al., 1994). While loss-of-function mutations have previously been associated with the PrfA $\mathrm{C}$ terminus (Herler et al., 2001; Roche et al., 2003; Velge et al., 2007), our results are the first, to our knowledge, to show that mutations within this region are capable of conferring high-level constitutive activation to this key virulence regulator.

The prfA P219S mutation is located within the $\alpha \mathrm{H}$ helix at the C-terminal end of PrfA. Based on the PrfA crystal structure, the three C-terminal alpha helices $(\alpha \mathrm{G}, \alpha \mathrm{H}$ and $\alpha \mathrm{I})$ form an extended region that has been postulated to contribute to stabilization of PrfA DNA binding through both intra- and intermolecular homodimer interactions (Eiting et al., 2005; Herler et al., 2001). Within an individual PrfA monomer, hydrogen bonds are formed between helices $\alpha \mathrm{H}$ and $\alpha \mathrm{I}$ with helices $\alpha \mathrm{C}$ and $\alpha \mathrm{D}$; PrfA mutants lacking the last $17 \mathrm{C}$-terminal residues $(\alpha \mathrm{H}$ and $\alpha \mathrm{I})$ lose all ability to bind DNA (Eiting et al., 2005; Herler et al., 2001). In addition, the intermolecular contacts made between the helices of $\alpha \mathrm{G}, \alpha \mathrm{H}$ and $\alpha \mathrm{I}$ of one PrfA monomer and $\beta 6$ and $\beta 7$ in the $\mathrm{N}$ terminus of the second monomer reportedly stabilize the monomer-monomer interface (Eiting et al., 2005). Residues participating in these contacts include K220 and Q223 in $\alpha \mathrm{H}$ and T82 in $\beta 6-\beta 7$. The $\mathrm{K} 220$ residue has previously been implicated as playing an important role in PrfA activity in that a K220T mutant exhibited reduced PrfA DNA binding without affecting dimer formation (Roche et al., 2003; Velge et al., 2007). It was thus somewhat surprising that mutants containing the adjacent P219S substitution exhibited only modest alterations in both PrfA DNA binding and PrfA dimer formation, but nevertheless exhibited high level activation of PrfA and a corresponding dramatic increase in PrfA-dependent gene expression.

How does the prfA P219S substitution induce PrfA activation? In the absence of structural data for this mutant protein, the precise mechanism remains unclear. PrfA activation in the absence of a significant increase in PrfA in vitro DNA-binding affinity has been reported for one additional $p r f A^{*}$ mutant, prfA Y63C (Miner et al., 2008b). The prfA Y63C mutation is located within a structural pocket that has been suggested to serve as the PrfA cofactorbinding site (Fig. 1b) and thus has been speculated to influence cofactor binding (Miner et al., 2008b). The prfA P219S mutation is not located near the putative cofactorbinding region and is not therefore anticipated to enhance or influence cofactor binding unless it does so via a distal conformational effect. Such a distal effect is possible given that the P219 residue is located at the end of PrfA $\alpha \mathrm{H}$, near the transition of helix $\mathrm{G}$ to helix H. $\alpha \mathrm{H}$ is in close proximity to $\alpha \mathrm{D}$, which contains G145 (Fig. 1b), for which the substitution of serine results in a repositioning of the PrfA helix-turn-helix DNA-binding domain and an increase in PrfA DNA-binding affinity (Eiting et al., 2005). While it is possible that the $\mathrm{P} 219 \mathrm{~S}$ substitution alters the conformation of $\alpha \mathrm{H}$ so as to mimic an activated state, the change imposed must be distinct from that conferred by G145S as there is no evident increase in PrfA P219S DNA-binding affinity (Fig. 4). Alternatively, it has been postulated that a component of the phosphoenol pyruvate phosphotransferase system may bind and sequester PrfA, thereby preventing PrfA binding at target promoters (Joseph \& Goebel, 2007; Marr et al., 2006; Mertins et al., 2007). If this is the case, it is possible that the prfA P219S mutation disrupts this inhibitory interaction and prevents sequestration of PrfA, leaving it free to bind and activate its target promoters. Although the precise in vivo mechanism underlying activation of PrfA remains speculative, the isolation and characterization of $p r f A^{*}$ mutant proteins has made it readily apparent that there are multiple types of PrfA activation via amino acid substitution.

\section{ACKNOWLEDGEMENTS}

We thank Erika Guerrero for assistance with PrfA CD studies and members of the Freitag lab and the UIC (Gram) Positive Thinking group for helpful discussions. This work was supported by Public Health Service grant AI41816 (N.E. F.). Its contents are solely the responsibility of the authors and do not necessarily represent the official views of the funding source.

\section{REFERENCES}

Alonzo, F., III, Port, G. C., Cao, M. \& Freitag, N. E. (2009). The posttranslocation chaperone PrsA2 contributes to multiple facets of Listeria monocytogenes pathogenesis. Infect Immun 77, 2612-2623. 
Bitar, A. P., Cao, M. \& Marquis, H. (2008). The metalloprotease of Listeria monocytogenes is activated by intramolecular autocatalysis. J Bacteriol 190, 107-111.

Bruno, J. C., Jr \& Freitag, N. E. (2010). Constitutive activation of PrfA tilts the balance of Listeria monocytogenes fitness towards life within the host versus environmental survival. PLOS ONE 5, e15138.

Camilli, A., Paynton, C. R. \& Portnoy, D. A. (1989). Intracellular methicillin selection of Listeria monocytogenes mutants unable to replicate in a macrophage cell line. Proc Natl Acad Sci U S A 86, 5522 5526.

Camilli, A., Tilney, L. G. \& Portnoy, D. A. (1993). Dual roles of plcA in Listeria monocytogenes pathogenesis. Mol Microbiol 8, 143-157.

Centers for Disease Control and Prevention (2004). Preliminary FoodNet data on the incidence of infection with pathogens transmitted commonly through food - selected sites, United States, 2003. MMWR Morb Mortal Wkly Rep 53, 338-343.

Cossart, P. (2007). Listeriology (1926-2007): the rise of a model pathogen. Microbes Infect 9, 1143-1146.

Cossart, P. \& Toledo-Arana, A. (2008). Listeria monocytogenes, a unique model in infection biology: an overview. Microbes Infect 10, 1041-1050.

Czuprynski, C. J. (2005). Listeria monocytogenes: silage, sandwiches and science. Anim Health Res Rev 6, 211-217.

Delgado, A. R. (2008). Listeriosis in pregnancy. J Midwifery Womens Health 53, 255-259.

Drevets, D. A. \& Bronze, M. S. (2008). Listeria monocytogenes: epidemiology, human disease, and mechanisms of brain invasion. FEMS Immunol Med Microbiol 53, 151-165.

Dussurget, O. (2008). New insights into determinants of Listeria monocytogenes virulence. Int Rev Cell Mol Biol 270, 1-38.

Eiting, M., Hagelüken, G., Schubert, W. D. \& Heinz, D. W. (2005). The mutation G145S in PrfA, a key virulence regulator of Listeria monocytogenes, increases DNA-binding affinity by stabilizing the HTH motif. Mol Microbiol 56, 433-446.

Freitag, N. E. (2006). From hot dogs to host cells: how the bacterial pathogen Listeria monocytogenes regulates virulence gene expression. Future Microbiol 1, 89-101.

Freitag, N. E. \& Portnoy, D. A. (1994). Dual promoters of the Listeria monocytogenes prfA transcriptional activator appear essential in vitro but are redundant in vivo. Mol Microbiol 12, 845-853.

Freitag, N. E., Port, G. C. \& Miner, M. D. (2009). Listeria monocytogenes - from saprophyte to intracellular pathogen. Nat Rev Microbiol 7, 623-628.

Gandhi, M. \& Chikindas, M. L. (2007). Listeria: a foodborne pathogen that knows how to survive. Int J Food Microbiol 113, 1-15.

Gray, M. J., Freitag, N. E. \& Boor, K. J. (2006). How the bacterial pathogen Listeria monocytogenes mediates the switch from environmental Dr. Jekyll to pathogenic Mr. Hyde. Infect Immun 74, 25052512.

Harman, J. G. (2001). Allosteric regulation of the cAMP receptor protein. Biochim Biophys Acta 1547, 1-17.

Harman, J. G., McKenney, K. \& Peterkofsky, A. (1986). Structurefunction analysis of three cAMP-independent forms of the cAMP receptor protein. J Biol Chem 261, 16332-16339.

Herler, M., Bubert, A., Goetz, M., Vega, Y., Vazquez-Boland, J. A. \& Goebel, W. (2001). Positive selection of mutations leading to loss or reduction of transcriptional activity of PrfA, the central regulator of Listeria monocytogenes virulence. J Bacteriol 183, 5562-5570.

Ireton, K. \& Cossart, P. (1997). Host-pathogen interactions during entry and actin-based movement of Listeria monocytogenes. Annu Rev Genet 31, 113-138.
Joseph, B. \& Goebel, W. (2007). Life of Listeria monocytogenes in the host cells' cytosol. Microbes Infect 9, 1188-1195.

Kreft, J., Vázquez-Boland, J. A., Altrock, S., Dominguez-Bernal, G. \& Goebel, W. (2002). Pathogenicity islands and other virulence elements in Listeria. Curr Top Microbiol Immunol 264, 109-125.

Lampidis, R., Gross, R., Sokolovic, Z., Goebel, W. \& Kreft, J. (1994). The virulence regulator protein of Listeria ivanovii is highly homologous to PrfA from Listeria monocytogenes and both belong to the Crp-Fnr family of transcription regulators. Mol Microbiol 13, 141-151.

Lauer, P., Chow, M. Y., Loessner, M. J., Portnoy, D. A. \& Calendar, R. (2002). Construction, characterization, and use of two Listeria monocytogenes site-specific phage integration vectors. $J$ Bacteriol 184, 4177-4186.

Lecuit, M. (2007). Human listeriosis and animal models. Microbes Infect 9, 1216-1225.

Lynch, M., Painter, J., Woodruff, R., Braden, C. \& Centers for Disease Control and Prevention (2006). Surveillance for foodborne-disease outbreaks - United States, 1998-2002. MMWR Surveill Summ 55, $1-42$.

Marquis, H., Doshi, V. \& Portnoy, D. A. (1995). The broad-range phospholipase $\mathrm{C}$ and a metalloprotease mediate listeriolysin $\mathrm{O}$ independent escape of Listeria monocytogenes from a primary vacuole in human epithelial cells. Infect Immun 63, 4531-4534.

Marr, A. K., Joseph, B., Mertins, S., Ecke, R., Müller-Altrock, S. \& Goebel, W. (2006). Overexpression of PrfA leads to growth inhibition of Listeria monocytogenes in glucose-containing culture media by interfering with glucose uptake. J Bacteriol 188, 3887-3901.

Mead, P. S., Dunne, E. F., Graves, L., Wiedmann, M., Patrick, M., Hunter, S., Salehi, E., Mostashari, F., Craig, A. \& other authors (2006). Nationwide outbreak of listeriosis due to contaminated meat. Epidemiol Infect 134, 744-751.

Mertins, S., Joseph, B., Goetz, M., Ecke, R., Seidel, G., Sprehe, M., Hillen, W., Goebel, W. \& Müller-Altrock, S. (2007). Interference of components of the phosphoenolpyruvate phosphotransferase system with the central virulence gene regulator PrfA of Listeria monocytogenes. J Bacteriol 189, 473-490.

Miner, M. D., Port, G. C., Bouwer, H. G., Chang, J. C. \& Freitag, N. E. (2008a). A novel prfA mutation that promotes Listeria monocytogenes cytosol entry but reduces bacterial spread and cytotoxicity. Microb Pathog 45, 273-281.

Miner, M. D., Port, G. C. \& Freitag, N. E. (2008b). Functional impact of mutational activation on the Listeria monocytogenes central virulence regulator PrfA. Microbiology 154, 3579-3589.

Mueller, K. J. \& Freitag, N. E. (2005). Pleiotropic enhancement of bacterial pathogenesis resulting from the constitutive activation of the Listeria monocytogenes regulatory factor PrfA. Infect Immun 73, 1917 1926.

O’Neil, H. S. \& Marquis, H. (2006). Listeria monocytogenes flagella are used for motility, not as adhesins, to increase host cell invasion. Infect Immun 74, 6675-6681.

Port, G. C. \& Freitag, N. E. (2007). Identification of novel Listeria monocytogenes secreted virulence factors following mutational activation of the central virulence regulator, PrfA. Infect Immun 75, 58865897.

Portnoy, D. A., Jacks, P. S. \& Hinrichs, D. J. (1988). Role of hemolysin for the intracellular growth of Listeria monocytogenes. J Exp Med 167, 1459-1471.

Ramaswamy, V., Cresence, V. M., Rejitha, J. S., Lekshmi, M. U., Dharsana, K. S., Prasad, S. P. \& Vijila, H. M. (2007). Listeria - review of epidemiology and pathogenesis. J Microbiol Immunol Infect 40, $4-13$. 
Ripio, M. T., Domínguez-Bernal, G., Lara, M., Suárez, M. \& VazquezBoland, J. A. (1997). A Gly145Ser substitution in the transcriptional activator PrfA causes constitutive overexpression of virulence factors in Listeria monocytogenes. J Bacteriol 179, 1533-1540.

Roche, S. M., Gracieux, P., Albert, I., Gouali, M., Jacquet, C., Martin, P. M. \& Velge, P. (2003). Experimental validation of low virulence in field strains of Listeria monocytogenes. Infect Immun 71, 3429-3436.

Scortti, M., Monzó, H. J., Lacharme-Lora, L., Lewis, D. A. \& VázquezBoland, J. A. (2007). The PrfA virulence regulon. Microbes Infect 9 , 1196-1207.

Shetron-Rama, L. M., Marquis, H., Bouwer, H. G. \& Freitag, N. E. (2002). Intracellular induction of Listeria monocytogenes actA expression. Infect Immun 70, 1087-1096.

Shetron-Rama, L. M., Mueller, K., Bravo, J. M., Bouwer, H. G., Way, S. S. \& Freitag, N. E. (2003). Isolation of Listeria monocytogenes mutants with high-level in vitro expression of host cytosol-induced gene products. Mol Microbiol 48, 1537-1551.

Smith, M. A., Takeuchi, K., Anderson, G., Ware, G. O., McClure, H. M., Raybourne, R. B., Mytle, N. \& Doyle, M. P. (2008). Dose-response model for Listeria monocytogenes-induced stillbirths in nonhuman primates. Infect Immun 76, 726-731.

Smith, B., Kemp, M., Ethelberg, S., Schiellerup, P., Bruun, B. G., Gerner-Smidt, P. \& Christensen, J. J. (2009). Listeria monocytogenes: maternal-foetal infections in Denmark 1994-2005. Scand J Infect Dis 41, 21-25.

Sun, A. N., Camilli, A. \& Portnoy, D. A. (1990). Isolation of Listeria monocytogenes small-plaque mutants defective for intracellular growth and cell-to-cell spread. Infect Immun 58, 3770-3778.

Swaminathan, B. \& Gerner-Smidt, P. (2007). The epidemiology of human listeriosis. Microbes Infect 9, 1236-1243.

Swaminathan, B., Gerner-Smidt, P. \& Whichard, J. M. (2006). Foodborne disease trends and reports. Foodborne Pathog Dis 3, 316-318.

Tan, G. S., Kelly, P., Kim, J. \& Wartell, R. M. (1991). Comparison of cAMP receptor protein (CRP) and a cAMP-independent form of CRP by Raman spectroscopy and DNA binding. Biochemistry 30, 50765080

Toledo-Arana, A., Dussurget, O., Nikitas, G., Sesto, N., GuetRevillet, H., Balestrino, D., Loh, E., Gripenland, J., Tiensuu, T. \& other authors (2009). The Listeria transcriptional landscape from saprophytism to virulence. Nature 459, 950-956.

Vázquez-Boland, J. A., Kuhn, M., Berche, P., Chakraborty, T., Dominguez-Bernal, G., Goebel, W., González-Zorn, B., Wehland, J. \& Kreft, J. (2001). Listeria pathogenesis and molecular virulence determinants. Clin Microbiol Rev 14, 584-640.

Vega, Y., Dickneite, C., Ripio, M. T., Böckmann, R., González-Zorn, B., Novella, S., Domínguez-Bernal, G., Goebel, W. \& Vázquez-Boland, J. A. (1998). Functional similarities between the Listeria monocytogenes virulence regulator PrfA and cyclic AMP receptor protein: the PrfA* (Gly145Ser) mutation increases binding affinity for target DNA. J Bacteriol 180, 6655-6660.

Vega, Y., Rauch, M., Banfield, M. J., Ermolaeva, S., Scortti, M., Goebel, W. \& Vázquez-Boland, J. A. (2004). New Listeria monocytogenes $\operatorname{prfA}^{\star}$ mutants, transcriptional properties of $\mathrm{PrfA}^{\star}$ proteins and structure-function of the virulence regulator PrfA. Mol Microbiol 52, 1553-1565.

Velge, P., Herler, M., Johansson, J., Roche, S. M., Témoin, S., Fedorov, A. A., Gracieux, P., Almo, S. C., Goebel, W. \& Cossart, P. (2007). A naturally occurring mutation K220T in the pleiotropic activator PrfA of Listeria monocytogenes results in a loss of virulence due to decreasing DNA-binding affinity. Microbiology 153, 995-1005.

Wong, K. K. \& Freitag, N. E. (2004). A novel mutation within the central Listeria monocytogenes regulator PrfA that results in constitutive expression of virulence gene products. J Bacteriol 186, 6265-6276.

Wong, K. K., Bouwer, H. G. \& Freitag, N. E. (2004). Evidence implicating the $5^{\prime}$ untranslated region of Listeria monocytogenes actA in the regulation of bacterial actin-based motility. Cell Microbiol 6, 155-166.

Xayarath, B., Marquis, H., Port, G. C. \& Freitag, N. E. (2009). Listeria monocytogenes $\mathrm{CtaP}$ is a multifunctional cysteine transport-associated protein required for bacterial pathogenesis. Mol Microbiol 74, 956973.

Youngman, P. (1987). Plasmid vectors recovering and exploiting Tn917 transposons in Bacillus and other Gram-positive bacteria. In Plasmids: a Practical Approach, 1st edn, pp 79-103. Edited by K. G. Hardy. Oxford: IRL Press.

Edited by: T. Msadek 